\title{
Использование золь-гель метода при нанесении полиэтиленгликоля на поликапиллярные колонки
}

\author{
Науменко И.И., Соболева В.К. \\ ${ }^{I}$ Федеральное государственное бюджетное учреждение науки Институт нефтегазовой геологии и \\ геофизики им. А.А. Трофимука СО РАН, Новосибирск \\ ${ }^{2} О O О$ «Мультихром», Новосибирск
}

Поступила в редакцию 10.04.2017 г.

Нанесение неподвижной фазы (НФ) полиэтиленгликоль (ПЭГ) торговой марки Carbowax 20M на поликапиллярные колонки (ПКК) при использовании золь-гель метода приводит к получению высокоэффективных хроматографических колонок с иммобилизованной НФ. При оптимальном времени созревания используемого для создания слоя НФ золь-геля, равном 24-36 ч, степень иммобилизации составляет 80-92\%. Полученные колонки демонстрируют повышенную термостойкость и пониженный уровень фона, вызванный уносом НФ.

Ключевые слова: газовая хроматография, скоростная хроматография, поликапиллярные колонки, нанесение неподвижных фаз, золь-гель метод, полиэтиленгликоль.

\section{Application of sol-gel method in poly(ethyleneglycol) coating to multicapillary columns}

\author{
Naumenko I.I. ${ }^{1}$, Soboleva V.K. ${ }^{2}$ \\ ${ }^{I}$ Trofimuk Institute of Petroleum Geology and Geophysics of Siberian Branch of Russian Academy \\ of Sciences (IPGG SB RAS), Novosibirsk \\ ${ }^{2}$ Multichrom Ltd., Novosibirsk
}

Polyglycols are referred to the most frequently used stationary phases (SP) in gas chromatography due to its high specificity to polar \& polarized sorbates. However they have some typical shortcomings, limiting their wider application, such as: a narrow temperature range, instability in oxidation, limited operating time, etc. One of the ways to improve the field-performance data of poly(ethylene glycol) (PEG) capillary columns provides the use of sol-gel technology based on hydrolysis products of alkoxysilanes. During the sol-gel reactions on a surface of capillaries a layer polysilicic acid is being formed. This layer consists of the stationary phase molecules with the covalent bonds partially formed. As a result it becomes non-extractable to provide for the columns high thermal stability and operational sustainability. The multicapillary PEG columns with Carbowax $20 \mathrm{M}^{\mathrm{TM}}$ also have the shortcomings typical for polyglycols. The study investigates the opportunity of PEG coating to the multicapillary columns with the sol-gel method being used to improve its field-performance data.

In the current study there are direct multi-channeled tubes made of C89-1 type glass (with a capillary ID about $40 \mathrm{um}$ ) used as a raw material. The precursor used for the coating of the SP is prepared according to the sol-gel technology from tetraethoxysilane, trifluoroacetic acid as a catalyst and methylene chloride containing Carbowax 20M. The sol-gel to be ready the mixture was kept at room temperature for some time, then it was diluted by chloroform. Prepared solution was used to coat the SP to the multicapillary columns by the static low pressure method.

At the time of sol-gel being ready from 24 to 36 hours during the coating there are high-efficient MCC with the immobilized SP as a result (3000-4200 theoretical plates for the sorbates with the retention factor $\mathrm{k}>10$ and the length $\approx 0,25 \mathrm{~m}$ ). The chromatographic characteristics of such columns were close to 
the ones, made by basic technology. During for more or less time of sol-gel being ready the gas chromatography columns with less selectivity or less degree of immobilization are made as a result.

The study of sol-gel MCCs characteristics revealed its increased thermal stability as it work out at $240^{\circ} \mathrm{C}$ during 20 hours relatively unchanged, while the others made by basic technology degrade in 3 hours. In addition, the investigated MCCs demonstrate low bleeding.

So, during the coating of SP Carbowax 20M to multicapillary tubes with the sol-gel method being used there are high efficient MCCs with the stationary phase with an immobilized coat. The immobilization degree of stationary phase with the optimal time of 24-36 h. for sol-gel is being ready accounts for $80-92 \%$. The columns characterized by increased thermal stability and reduced bleeding than the ones obtained by the basic technology. Apparently, this result caused by the stable three-dimensional organic-inorganic polymer formed from the PEG along with the products of hydrolysis of tetraethoxysilane.

Keywords: gas chromatography, high speed gas chromatography, multicapillary columns, stationary phase coating, poly(ethylene glycol).

\section{Введение}

Газохроматографические колонки с полигликолями в качестве неподвижных фаз получили широкое применение в хроматографической практике для разделения полярных и поляризуемых веществ [1-5]. Их уникальная специфичность позволяет разделять сорбаты с одинаковой температурой кипения, что затруднительно для колонок с широко используемыми силиконовыми НФ [6]. Однако полигликолям присущи существенные недостатки, препятствующие их большему распространению, а именно: ограниченная термостойкость $[1,7]$, склонность к деградации или уносу НФ при повышенной температуре $[1,8,9]$, легкость окисления кислородом, входящим в состав пробы или газа-носителя [7,9].

Одним из способов повышения термостойкости и улучшения эксплуатационных характеристик неподвижных фаз, нанесенных на сорбенты или капиллярные колонки, является их иммобилизация, о чем свидетельствуют имеющиеся обзоры [5, 10-12]. Иммобилизация - способ стабилизации пленки полимерной неподвижной фазы путем межмолекулярной сшивки или (и) прививки к сорбенту или стенкам колонки. В результате иммобилизации НФ становится неэкстрагируемой растворителями, что заметно упрощает эксплуатацию и регенерацию колонок, повышает воспроизводимость и стабильность хроматографических колонок, расширяет область рабочих температур [12]. В то время, как способы иммобилизации полисилоксановых НФ хорошо отработаны и внедрены в практику, методы иммобилизации полигликолей сопряжены с определенными трудностями и находятся на стадии совершенствования [12]. По этой причине весьма актуальным было появление статей и патентов [13-23], в которых предложен одностадийный метод изготовления капиллярных колонок, включающий нанесение и иммобилизацию плёнки НФ с одновременной дезактивацией поверхности капилляров, основанный на использовании зольгель технологий. Помимо значительного сокращения времени изготовления, полученные образцы капиллярных колонок демонстрировали отличную селективность и повышенную термическую устойчивость. В течение золь-гель процесса при гидролизе алкоксисиланов образуется поликремниевая кислота, при поликонденсации которой с молекулами НФ образуется органо-неорганический полимер, химически связанный с поверхностью кварца и блокирующий ее активность. По существу происходит эффективная химическая иммобилизация неподвижной фазы с фиксацией ее на поверхности, придающая колонкам высокую термическую и эксплуатационную устойчивость.

Коммерческие фирмы предлагают большое количество хроматографических колонок, как наполненных, так и капиллярных с полимерными гликолями, в том числе модифицированными различными функциональными группами. Производитель скоростных ПКК также предлагает колонки, покрытые полиэтиленгликолем 
(ПЭГ) торговой марки Carbowax 20M [24], при этом отмечает, что они не очень стабильно работают при температуре выше $180^{\circ} \mathrm{C}$, а заявленная максимальная температура эксплуатации колонок составляет $200^{\circ} \mathrm{C}$, что меньше величины, рекомендованной для этой НФ $\left(225^{\circ} \mathrm{C}\right)$ [25]. С целью улучшения эксплуатационных характеристик ПКК и повышения их термоустойчивости в настоящей работе исследована возможность нанесения ПЭГ на ПКК с привлечением золь-гель метода.

\section{Эксперимент}

В работе использованы тетраэтоксисилан производства фирмы «Fluka», полиэтиленгликоль торговой марки Carbowax 20M («Supelco»), трифторуксусная кислота («Вектон») и растворители квалификации х.ч.

В качестве исходного материала для приготовления ПКК применяли прямые многоканальные трубки (МКТ) шестигранного сечения с размером по апофеме 2.2 мм, изготовленные из электровакуумного стекла марки С 89-1, количество капилляров в пучке 1387, диаметр капилляра около 40 мкм. Начальная длина МКТ составляла 0.28-0.3 м. Перед нанесением НФ МКТ подвергнуты обработке минеральной кислотой, затем промыты 40 мл дистиллированной воды под давлением аргона, помещены в термостат хроматографа и высушены в потоке аргона $\left(40 \mathrm{~cm}^{3} / \mathrm{Mин}\right)$ в режиме программирования температуры от 40 до $250^{\circ} \mathrm{C}$ и выдержаны при конечной температуре 1 ч. Прекурсор для нанесения готовили следующим образом: во флаконе с плотно завинчивающейся крышкой объемом $10 \mathrm{~cm}^{3}$ растворяли 150 мг Carbowax $20 \mathrm{M} \mathrm{в} 500$ мкл хлористого метилена, добавляли 100 мкл тетраэтоксисилана и встряхивали несколько раз. Помещали флакон в ультразвуковую ванну, включали ультразвук и добавляли к раствору 45 мкл 95\% водного раствора трифторуксусной кислоты, после чего воздействие ультразвуком продолжали еще 10 мин. Рабочий раствор для нанесения НФ готовили разбавлением прекурсора пятью см ${ }^{3}$ хлороформа, непосредственно перед нанесением его дегазировали в ультразвуковой ванне в течение нескольких минут. Процедуру нанесения пленки НФ и последующего кондиционирования ПКК проводили, как описано ранее [26], максимальная температура кондиционирования составляла $240^{\circ} \mathrm{C}$. После каждой технологической операции МКТ обрезали с обеих сторон на 2-3 мм, конечная длина ПКК составляла 250-260 мм.

Промывку колонок осуществляли прокачивая растворитель (хлороформ) объемом $10 \mathrm{~cm}^{3}$ через ПКК давлением аргона ( 0.2 Мпа), после этого помещали ПКК в термостат хроматографа, присоединяли один из концов к испарителю и нагревали в потоке газа-носителя от 50 до $200^{\circ} \mathrm{C}$ со скоростью $10^{\circ} \mathrm{C} /$ мин и выдерживали при конечной температуре 0.5-1ч. ПКК с НФ Carbowax 20M, нанесенной по ранее существующей технологии для проведения сравнительных испытаний предоставлены ООО «Мультихром». При подготовке растворов использовали ультразвуковую ванну Cole-Parmer 8891.

Газохроматографические измерения выполняли на модернизированном хроматографе Цвет-800, снабженным серийным пламенно-ионизационным детектором, устройством быстрого ввода пробы, описанным в работе [27], и оригинальным электрометрическим усилителем с постоянной времени 2 мс. Состав тестовой смеси и процедура газохроматографирования аналогична используемой ранее [26]. Условия газохроматографического разделения тестовой смеси: поток газа-носителя (азот или аргон) составлял 35-40 cм 3 /мин, температура термостата колонок $125^{\circ} \mathrm{C}$, температура испарителя и детектора $250^{\circ} \mathrm{C}$. Для обработки результатов использовали программу «Изида 2.2» (ООО Мультихром), работающую в среде Windows ${ }^{\mathrm{TM}}$. Качество ПКК оценивали по эффективности последнего пика на хроматограмме, выраженной числом теоретических тарелок (т.т.). 


\section{Обсуждение результатов}

В работе использовали прекурсор, приготовленный по золь-гель технологии из тетраэтоксисилана, трифторуксусной кислоты (катализатор) и ПЭГ Carbowax $20 \mathrm{M}$, растворитель - хлористый метилен. Для созревания золь-геля смесь выдерживали при комнатной температуре в течение некоторого времени. Перед нанесением прекурсор разбавляли хлороформом, полученный рабочий раствор использовали в течение двух суток, позже из него начинает выпадать объемный желеобразный осадок.

Нанесение НФ на МКТ осуществляли статическим методом низкого давления коррелированным образом, при котором в капилляры большего диаметра вносится большее количество неподвижной фазы, что позволяет существенно увеличить эффективность получаемых ПКК [28, 29].

При времени созревания золь-геля от 24 до 36 ч при нанесении получены ПКК с высокой эффективностью разделения (3000-4200 т. т. для сорбатов с фактором удерживания $k>10$ ). В качестве примера на рисунке 1 приведена хроматограмма разделения теста Гроба на одной из полученных колонок. Видно, что хроматографические пики веществ с различной полярностью симметричны, что свидетельствует об отсутствии активности поверхности стекла и НФ. Следует отметить, что характеристики ПКК (эффективность, времена удерживания веществ, симметрия пиков), полученных с применением золь-гель метода и существующей ранее базовой технологии очень близки.

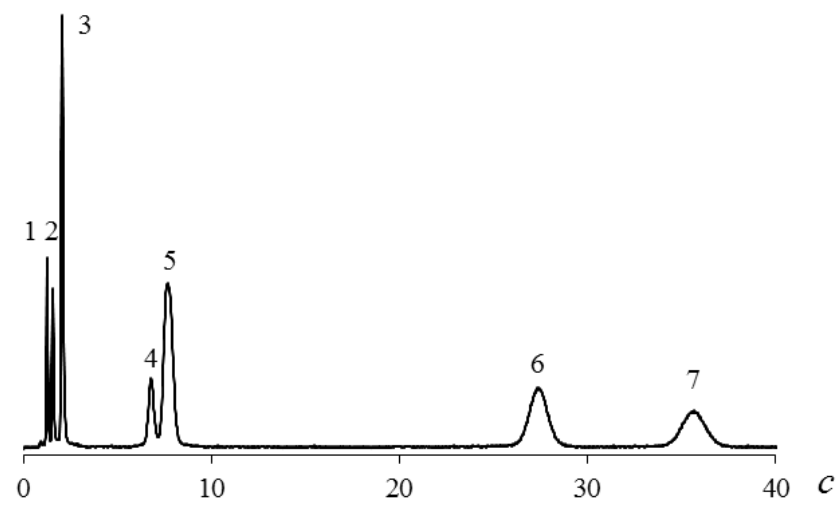

Рис. 1. Хроматограмма теста Гроба на ПКК с неподвижной фазой Carbowax-20M, нанесенной с использованием золь-гель технологии. Цифрами обозначены пики: 1 - н-декан, 2 - н-ундекан, 3 - н-додекан, 4 - 2,3-бутандиол, 5 - 1-октанол, 6 - 2,6-диметиланилин, 7 - 2,6-диметилфенол.

Степень иммобилизации (сшивки) НФ оценивали сравнением факторов удерживания по одному и тому же сорбату перед промывкой и после промывки готовых колонок хлороформом с целью удаления несвязанной НФ. Объем используемого при промывке растворителя намного превышает необходимый для полного растворения всей НФ, содержащейся в колонке. Степень сшивки НФ $\alpha(\%)$ вычисляли по уравнению:

$$
\alpha=\frac{k_{2}}{k_{1}} \times 100,
$$

где $k_{1}$ и $k_{2}$ - факторы удерживания по веществу при одинаковых условиях до и после промывки колонки растворителем с последующим кондиционированием, соответственно. Следует отметить, что следующие промывки колонок, в том числе после их эксплуатации, не приводят к заметному уменьшению количества НФ в ПКК. 
В результате проведенных экспериментов показано, что в вышеописанных условиях степень сшивки НФ составила 80-92 \%, т.е. во время протекания золь-гель процессов, последующего нанесения и нагревания, НФ подвергается иммобилизации. Для одной из полученных ПКК в таблице приведены времена удерживания $\left(t_{1}\right.$ и $\left.t_{2}\right)$ и факторы удерживания $\left(k_{1}\right.$ и $\left.k_{2}\right)$ для компонент теста Гроба соответственно до и после промывки растворителем, а также степени сшивки НФ по каждому веществу. При расчетах факторов удерживания в качестве пика с нулевым временем удерживания использовали пик метана. Из представленных данных видно, что степень сшивки по неполярным н-углеводородам меньше, чем по полярным веществам, т.е. в результате промывки происходит небольшое повышение полярности НФ. Аналогичный результат получен в работе [18] для золь-гель капиллярных колонок с ПЭГ, что авторы статьи объясняют вымыванием менее полярных компонент из нанесенного органо-неорганического слоя полимера.

Таблица. Времена и факторы удерживания веществ теста Гроба и степень сшивки НФ Carbowax 20M, нанесенной на ПКК золь-гель методом.

\begin{tabular}{|c|c|c|c|c|c|}
\hline \multirow{2}{*}{ Вещество } & \multicolumn{2}{|c|}{ До промывки } & \multicolumn{2}{|c|}{ После промывки } & $\begin{array}{c}\text { Степень } \\
\text { сшивки, } \alpha, \\
\%\end{array}$ \\
\cline { 1 - 5 } & $t_{1}, c$ & $k_{1}$ & $t_{2}, c$ & $k_{2}$ & \\
\hline Метан & 0.92 & & 0.91 & & 78.6 \\
\hline н-Декан & 1.28 & 0.39 & 1.2 & 0.31 & 79.0 \\
\hline н-Ундекан & 1.56 & 0.70 & 1.42 & 0.55 & 79.4 \\
\hline н-Додекан & 2.04 & 1.22 & 1.8 & 0.97 & 83.9 \\
\hline 2,3-Бутандиол & 7.28 & 6.91 & 6.2 & 5.80 & 8.5 \\
\hline 1-Октанол & 7.96 & 7.65 & 7.08 & 6.77 & 84.8 \\
\hline 2,6-Диметиланилин & 26.58 & 27.89 & 22.32 & 23.52 & \\
\hline 2,6-Диметилфенол & 34.08 & 36.04 & 28.74 & 30.57 & 84.8 \\
\hline
\end{tabular}

При меньшем времени созревания золь-геля получены ПКК с высокой или удовлетворительной селективностью (эффективность от 2000 до 3500 т.т.), но степень сшивки НФ не превышала 80\%, при большем - малоэффективные хроматографические колонки с эффективностью менее 1500 т.т. Прекурсор, оставленный в течение 7-10 дней, становится желеобразным и непригодным для заполнения МКТ, часто также наблюдается выпадение белого студенистого осадка. Таким образом, оптимальное время для созревания золь-геля с целью приготовления наиболее эффективных ПКК и наибольшей степени сшивки НФ лежит в интервале 24-36 ч.

Вследствие того, что в полученных ПКК НФ иммобилизирована, в случае загрязнения в результате интенсивной эксплуатации или экстраординарных ситуаций они могут быть промыты растворителем с возможным восстановлением селективности. Однако характеристики промытых колонок будут отличаться от исходных, т.к. степень сшивки НФ всегда меньше 100\%, следовательно, факторы удерживания для всех сорбатов с $k>0$ уменьшатся при промывке, кроме того, как отмечено выше, при этом изменяется полярность НФ.

Были исследованы некоторые характеристики ПКК с Carbowax-20M, в частности, их термическая устойчивость. Установлено, что золь-гель колонки допускают эксплуатацию при максимальной температуре $240^{\circ} \mathrm{C}$, что существенно выше, чем для изготовленных по базовой технологии. Сравнительная термостойкость колонок ПКК с ПЭГ, нанесенным разными способами, была оценена путем нагревания образцов колонок в потоке инертного газа (азот) при температуре $240^{\circ} \mathrm{C}$. На рисунке 2 приведены полученные экспериментальные зависимости относительной эффектив- 
ности ПКК (отношение наблюдаемой $(N)$ к начальной $\left(N_{0}\right)$ эффективности) от времени нагрева.

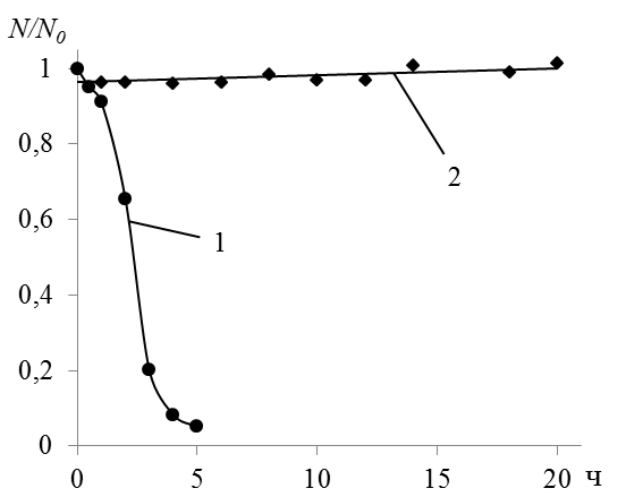

Рис. 2. Зависимость относительной эффективности ПКК с нанесенной НФ Carbowax-20M по базовой (1) и золь-гель технологии (2) от времени нагревания в потоке азота при температуре $240^{\circ} \mathrm{C}$.

Видно, что для золь-гель ПКК эффективность в т.т. практически не меняется в течение 20 ч, тогда как ПКК, изготовленная по базовой технологии, деградирует в течение 3 ч, ее эффективность падает с 3700 до 185 т.т. Таким образом, применение нового метода позволило поднять максимальную температуру эксплуатации ПКК с ПЭГ на $40^{\circ} \mathrm{C}$. Повышенную термостойкость колонок, можно объяснить, повидимому, образованием на поверхности капилляров устойчивого пространственного органо-неорганического полимера, состоящего из поликремниевой кислоты и включенного в него или химически связанного ПЭГ.

В процессе вышеописанного эксперимента, для обеих колонок, проведена оценка уровня фона, вызванного уносом НФ: через 1 ч нагревания, абсолютный сигнал детектора, присоединенного к исследуемым колонкам, составил 80 и 18 пА для ПКК, полученных, соответственно, по базовой и золь-гель технологии, т.е. последние колонки демонстрируют существенно более низкий фон, вызванный уносом НФ. Это существенно облегчает возможность их использования при проведении экспресс анализов в тандеме с высокочувствительными детекторами.

ПКК с ПЭГ могут быть использованы для скоростного разделения смесей различных веществ, особенно полярных. В качестве примера такого разделения на рисунке 3 представлена хроматограмма разделения легких спиртов $\mathrm{C}_{2}-\mathrm{C}_{4}$.

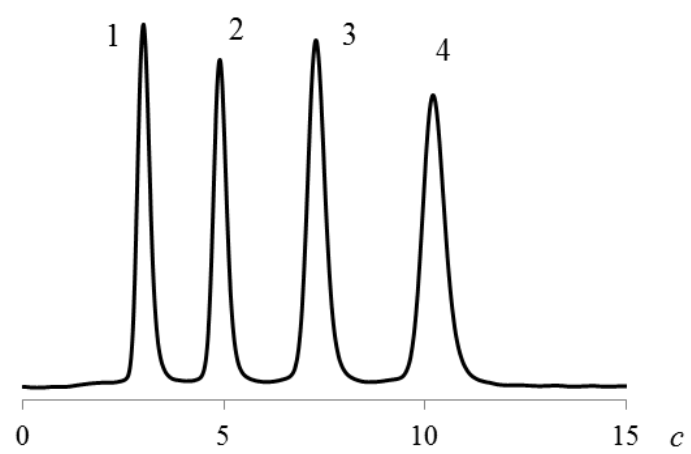

Рис. 3. Хроматограмма разделения спиртов на ПКК с Carbowax-20M, полученной по золь-гель технологии.

Условия хроматографирования: температура колонки $65^{\circ} \mathrm{C}$, испарителя и детектора (ПИД) - 200 и $250^{\circ} \mathrm{C}$ соответственно, поток газа-носителя (азот) 40 мл/мин. Пики: 1 - этанол + 2-пропанол, 2 - 2-бутанол, 3 - 2-метил-1-пропанол, 4 - 1-бутанол. 


\section{Заключение}

Применение золь-гель метода при нанесении НФ Carbowax 20M на ПКК позволяет получить высокоэффективные колонки с иммобилизированной пленкой НФ, при оптимальном времени созревания золь-геля, равном 24-36 ч, степень сшивки НФ составляет 80-92\%. Иммобилизация НФ позволяет при загрязнении колонки очистить ее промывкой растворителем. Полученные ПКК отличаются повышенной на $40^{\circ} \mathrm{C}$ максимальной температурой эксплуатации и пониженным уровнем фона по сравнению с колонками, приготовленными ранее существующим методом.

\section{Список литературы}

1. Руководство по газовой хроматографии. Часть 2. Под ред. Лейбница Э., Штруппе Х.Г. М. Мир. 1988. С. 143-148.

2. Король А.Н. Неподвижные фазы в газожидкостной хроматографии. М. Химия. 1985. $240 \mathrm{c}$.

3. Evans M.B., Smith J.E. // J. Chromatogr. 1968. Vol. 36. pp. 489-503.

4. Yancey J.A. // J. Chromatogr. Sci. 1994. Vol. 32. No 9. pp. 403-413.

5. Barry E.F. Columns: Packed and Capillary; Column Selection in Gas Chromatography: Modern practice of gas chromatography. 4th ed. Edit. Grob R.L., Barry E.F., Wiley, 2004, pp. 148-164

6. Yancey J.A. // J. Chromatogr. Sci. 1985. Vol. 23. No 8. pp. 370-377.

7. Ciganek M., Dressler M., Teply J.J. // Chromatogr. 1991. Vol. 588. pp. 225-230.

8. Keller R.A., Bate R., Costa B., Forman P.J. // Chromatogr. 1962. Vol. 8. pp.157-177.

9. Conder, J., Fruitwala N., Shingari, K. // J. Chromatogr. 1983. Vol. 269. pp.171-178.

10. Borek V., Hubacek J., Rehakova V. // Chem. Listy. 1985. Vol. 79. p. 364.

11. Blomberg L.G. // J. Microcol. Sep. 1990. Vol. 2. pp. 62-68.

12. Мухина В.П., Березкин В.Г., Левин Я.А. // Успехи химии. 1998. Т. 67. № 12. С. 11641174.

13. Guo Y., Colon L.A. // Anal. Chem. 1995. Vol. 67. pp. 2511-2516.

14. Wang D., Chong S.L., Malik A. // Anal. Chem. 1997. Vol. 69. pp. 4566-4576.

15. Hayes J.D., Malik A. // J. Chromatogr. B. 1977. Vol. 695. pp. 3-13.

16. Rodriguez S.A. // Chem. Mater. 1999. Vol. 11. pp.754-762.

\section{References}

1. Handbuch der Gaschromatographie. Herausgegeben von E. Leibnitz, G. Struppe. Akad. Verlagsgesellschaft Geest \& Portig, Leipzig
17. Kiridena W., Poole C.F., Koziol W.W. // Analyst. 2002. Vol. 127. pp. 1608-1613.

18. Shende C., Kabir A., Townsend E., Malik A // Anal. Chem. 2003. Vol. 75. No 14. pp. 3518-3530.

19. Malik A., Kabir A., Shende C. Patent USA. No 2007/0062874, 2007.

20.Gu X., Wang Y., Zhang X. // Chromatogr. 2005. Vol. 62. No 9/10. pp. 483-491.

22. Technical article: The importance of low bleed columns for GC-MS. URL: http://www.sge.com/uploads/0a/ea/0aeaf7d5c0a e608bbdf5a0ac81c6f100/TA-0063-C.pdf (дата обращения: 30.03 .2017$)$

23. Malik A., Kabir A., Shende C. Patent USA. No 8685240, 2014.

24. Поликапиллярные колонки для скоростной газовой хроматографии. URL: http://mcc-chrom.ru (дата обращения: 30.03.2017)

25. SUPELCO catalog 2000: Chromatography Products for Analysis and Purification. SigmaAldrich Co. USA. 2000. p. 38.

26. Науменко И.И., Соболева В.К.// Сорбиионные и хроматографические прочессы. 2016. T. 16. № 5. C. 591-599.

27 Науменко И.И., Ефименко А.П., Балдин М.Н., Грузнов В.М. // Датчики и системы. 2013. № 11. C. 51-55.

28. Ефименко А.П., Науменко И.И., Соболева В.К. // Журнал физической химии. 2007. T. 81. № 3. C. 488-492.

29. Ефименко А.П., Науменко И.И, Соболева В.К. Спринтеры в газовой хроматографии - поликапиллярные хроматографические колонки: Хроматография во благо России. М. Граница. 2007. С. 634-648.

1984, 828 S. (Russ. ed.: Rukovodstvo po gazovoi khromatografii. Edit. E. Leibnitz, G. 
Struppe. Russ. edit. Berezkin V.G. Moscow, Mir, 1988, pp. 143-148.

2. Korol' A.N. Nepodvizhnye fazy v gazozhidkostnoi khromatografi. Moscow, Khimiya, 1985, $240 \mathrm{p}$.

3. Evans M.B., Smith J.E., J. Chromatogr., 1968, Vol. 36, pp. 489-503.

4. Yancey J.A., J. Chromatogr. Sci., 1994, Vol. 32, No 9, pp. 403-413.

5. Barry E.F. Columns: Packed and Capillary; Column Selection in Gas Chromatography: Modern practice of gas chromatography. 4th ed. Edit. Grob R.L., Barry E.F., Wiley, 2004, pp. $148-164$

6. Yancey J. A., J. Chromatogr. Sci., 1985, Vol. 23, No 8, pp. 370-377.

7. Ciganek M.; Dressler M.; Teply J. J., Chromatogr., 1991, Vol. 588, pp. 225-230.

8. Keller R. A., Bate R., Costa, B., Forman P. J., Chromatogr., 1962, Vol. 8, pp.157-177.

9. Conder, J., Fruitwala N., Shingari, K., J., Chromatogr., 1983, Vol. 269, pp.171-178.

10. Borek V., Hubacek J., Rehakova V., Chem. Listy, 1985, Vol. 79, p. 364.

11. Blomberg L. G., J. Microcol. Sep., 1990, Vol. 2, pp. 62-68.

12. Mukhina V.P., Berezkin V.G., Levin Ya.A., Russian chemical reviews, 1998, Vol. 67, № 12. pp. 1164-1174.

13. Guo Y., Colon L.A., Anal. Chem., 1995, Vol. 67, pp. 2511-2516.

14. Wang D., Chong S.L., Malik A., Anal. Chem., 1997, Vol. 69, pp. 4566-4576.

15. Hayes J.D., Malik A., J. Chromatogr. B., 1977, Vol. 695, pp. 3-13.

16. Rodriguez S.A., Colon L.A., Chem. Mater., 1999, Vol. 11, pp.754-762.

Науменко Иван Иванович - к.х.н., старший научный сотрудник Федерального государственного бюджетного учреждения науки Института нефтегазовой геологии и геофизики им. А.А. Трофимука СО РАН, Новосибирск

Соболева Валентина Константиновна - ведущий инженер ООО «Мультихром», Новосибирск
17. Kiridena W., Poole C.F., Koziol W.W., Analyst., 2002, Vol. 127, pp. 1608-1613.

18. Shende C., Kabir A., Townsend E., Malik A., Anal. Chem., 2003, Vol. 75, No 14, pp. 3518-3530.

19. Malik A., Kabir A., Shende C. Patent USA, no. 2007/0062874, 2007.

20. Gu X., Wang Y., Zhang X., Chromatogr., 2005, Vol. 62, No 9/10, pp. 483-491.

22. Technical article: The importance of low bleed columns for GC-MS. URL: http://www.sge.com/uploads/0a/ea/0aeaf7d5c0a e608bbdf5a0ac81c6f100/TA-0063-C.pdf (accessed 30 March 2017)

23. Malik A., Kabir A., Shende C. Patent USA, no. 8685240, 2014.

24. Multicapillary Columns for the Fast Gas Chromatography. URL: http://mcc-chrom.com/ (accessed 30 March 2017)

25. SUPELCO catalog 2000: Chromatography Products for Analysis and Purification. Sigma-Aldrich Co., USA, 2000, p. 38.

26. Naumenko I. I, Soboleva V. K., Sorbtsionnye $i$ khromatograficheskie protsessy (Russ.), 2016, Vol. 16, No. 5, pp. 591-599.

27 Naumenko I. I., Efimenko A. P., Baldin M.N., Gruznov V.M., Sensors \& Systems, 2013, No.11, pp. 51-55.

28. Efimenko A. P., Naumenko I. I, Soboleva V. K., Russian J. Phys. Chem., 2007, Vol. 81, No. 3, pp. 488-492.

29. Efimenko A. P., Naumenko I. I., Soboleva V. K. Sprintery v gazovoi khromatografii-polikapillyarnye khromatograficheskie kolonki: Khromatografiya vo blago Rossii. Moscow, Granitsa, 2007, pp. 634-648.

Naumenko Ivan I., p.h.d., senior researcher of Trofimuk Institute of Petroleum Geology and Geophysics of Siberian Branch of Russian Academy of Sciences (IPGG SB RAS), Novosibirsk, E-mail: root@multichrom.nsk.ru

Soboleva Valentina K., lead engineer, Multichrom Ltd., Novosibirsk, E-mail: root@multichrom.nsk.ru 